\title{
EM BUSCA DE UMA POLÍTICA EXTERNA BRASILEIRA DE MEIO AMBIENTE três exemplos e uma exceção à regra
}

\author{
Marijane Vieira Lisboa
}

\begin{abstract}
Resumo: A política externa brasileira de meio ambiente carece de princípios claros, objetivos e estratégias. Por não compreender o que significa o desenvolvimento sustentável, o Itamarati freqüentemente privilegia os interesses econômicos de curto prazo, em detrimento da proteção do meio ambiente. A Convenção da Basiléia, o Protocolo de Cartagena e a Convenção de Estocolmo são três exemplos dessa tese, enquanto a Convenção de Mudanças Climáticas é a exceção que confirma a regra.

Palavras-chave: meio ambiente; política externa; desenvolvimento sustentável.
\end{abstract}

Abstract: Brazil's foreign environmental policy lacks clear principles, objectives and strategies. In its failure to understand the significance of sustainable development, the Itamaraty often favors short-term economic interests, to the detriment of environmental protection. The Basil Convention, the Cartagena Protocol and the Stockholm Convention are three supporting examples of this thesis, while the Convention on Climate Change is the exception that confirms the rule.

Key words: environment; foreign policy; sustainable development.

$\mathrm{S}$ ó uma conceituação muito frouxa do que seria política poderia permitir o uso do termo política externa brasileira de meio ambiente para qualificar um conjunto de posicionamentos ambíguos e contraditórios intercalados por omissões sistemáticas que tem dado o tom da atuação brasileira na esfera internacional, em relação aos temas ambientais. A famosa diplomacia brasileira, no campo ambiental, tem sido bastante medíocre e uma explicação para o fenômeno desafia observadores e atores envolvidos nas negociações internacionais. A exceção que confirma a regra é o caso da política brasileira na área da Convenção das Mudanças Climáticas, mas se verá, mais adiante, que as condições que permitiram o desenvolvimento de uma política coerente para essa problemática, não estiveram presentes em nenhum dos outros temas relevantes da política ambiental internacional.

A mediocridade da política ambiental brasileira contrasta tragicamente com as pretensões mais gerais da diplomacia brasileira de situar o Brasil como potência mundial, capaz de dialogar de igual para igual com os EUA, a União Européia e o bloco asiático, ao mesmo tempo em que se reivindica a posição de líder natural dos países latino-americanos, disputando ainda com a Índia a lideran- ça dos países em desenvolvimento. Três exemplos, a seguir, ilustram essa realidade.

\section{CONVENÇÃO DA BASILÉIA}

A Convenção da Basiléia começou a ser negociada em 1989 e pretendia dar conta do grave problema e, ao mesmo tempo, moralmente indecente crescimento das exportações de lixo perigoso do mundo industrializado para o mundo em desenvolvimento. Nos anos 80 , a crescente consciência ambiental no mundo industrializado criava enormes dificuldades à construção de novos aterros e incineradores para resíduos perigosos. Isso que veio a ser chamado de Nimby Efect - Not in my backyard - , traduzido como "não na minha vizinhança", aliado a legislações ambientais mais severas e aos novos compromissos internacionais de não mais se despejar resíduos perigosos nos oceanos, ${ }^{1}$ fez que os custos de manejo de lixo perigoso subissem vertiginosamente nos países industrializados. O comércio de lixo perigoso apresenta-se, então, como a alternativa, pois por baixos custos era possível encontrar companhias que comprassem esse lixo e o despejassem nos países em desenvolvimento. Ditadores corruptos de 
países africanos ou centro-americanos autorizavam a descarga de barris em praias desertas e áreas abandonadas, em troca de depósitos bancários em algum paraíso fiscal.

Também havia um outro destino para esse lixo perigoso. Fundições secundárias, que extraem metais com algum valor, partindo de resíduos industriais, como o chumbo, o zinco e o cobre, tinham interesse em adquirir essa "matéria-prima" barata. Em países recém- industrializados como o Brasil, a Índia, a Indonésia ou as Filipinas, existem dezenas de indústrias deste tipo, poluindo o meio ambiente com metais pesados como chumbo, mercúrio, cromo e arsênico, ao mesmo tempo em que condenam à invalidez sem assistência médica e previdenciária seus milhares de trabalhadores.

Por pressão dos países africanos, principais vítimas desse comércio imoral, a ONU começou a patrocinar negociações para elaborar uma convenção internacional, visando coibir esse comércio criminoso. A Convenção da Basiléia, no entanto, assinada em 1989 em Basiléia, decepcionou enormemente os países africanos, por excluir um dispositivo que proibiria a exportação de resíduos perigosos do Primeiro Mundo para os países em desenvolvimento. Essa exclusão deveu-se às pressões de última hora dos EUA, um dos maiores exportadores de resíduos perigosos para o mundo em desenvolvimento, juntamente com a Inglaterra e a Alemanha.

Em dezembro de 1992, a $1{ }^{a}$ Reunião das Partes da Convenção da Basiléia deu-se em Piriápolis, no Uruguai. Na mesa, novamente, uma proposta de resolução, apresentada pelo próprio secretário-geral do Programa das Nações Unidas para o Meio Ambiente, o sr. Mustafa Tolba, que propunha a proibição de exportação de resíduos perigosos para os países em desenvolvimento. Entretanto, devido à enorme resistência do bloco dos países desenvolvidos, capitaneados pelos EUA, Canadá, Austrália, Japão, Inglaterra e Alemanha, Mustafa Tolba retirou sua proposta. O Grupo 77 e China, porém, inconformados com o desenlace da reunião, deixaram registrado que pretendiam adotar e apresentar de novo a mesma proposta, na próxima reunião das Partes, o que ocorreria em março de 1994, em Genebra. Nessa reunião, finalmente, após calorosos debates e negociações que se arrastaram até alta madrugada, aprovou-se a resolução que passou a ser conhecida como a Proibição da Basiléia. Por essa resolução, a partir de fins de 1997 os países industrializados estariam impedidos de exportar resíduos perigosos para os países em desenvolvimento.

Como comportou-se o Brasil em relação a essas negociações? Em contatos com o Departamento de Meio Am- biente do Itamaraty (Dema), ainda antes da realização da $1^{\text {a }}$ Reunião das Partes, em Piriápolis, o Greenpeace diagnosticou certa resistência brasileira à aprovação de uma proibição total para importações de resíduos perigosos, em virtude do País costumeiramente importar resíduos perigosos de metalúrgicas, para extração de chumbo e outros metais perigosos. Devido ao fato de não possuirmos jazidas de chumbo e a importação de minério puro ser agravada por impostos especiais, tornava-se economicamente interessante para recicladoras de baterias automotivas no Brasil importar as baterias usadas dos EUA, de modo a recuperar-lhes o chumbo. Vale dizer, que a recuperação de chumbo, mesmo que realizada com a mais avançada tecnologia - o que não era o caso no Brasil - é uma operação altamente perigosa tanto para o meio ambiente, quanto para a saúde dos trabalhadores nela envolvidos.

Embora concordasse com o espírito geral da proposta de proibir as exportações de resíduos perigosos para o Terceiro Mundo, a existência de um setor econômico dentro do nosso próprio país contrário à essa proibição - ainda que fosse um setor de expressão econômica insignificante no conjunto da economia brasileira - levou o Itamaraty a assumir uma postura absolutamente discreta durante a 1를 Reunião das Partes, em Piriápolis.

Um ano e tanto depois, por solicitação do Greenpeace, o Ministro Rubens Ricúpero, na época Ministro do Meio Ambiente, convocou uma reunião informal do Conselho Nacional de Meio Ambiente para discutir a posição a ser tomada pelo Brasil na próxima reunião da Convenção, a segunda, a ser realizada em Genebra, em março de 1994. Presentes diversos secretários de meio ambiente, deputados e entidades ambientalistas, o Ministro declarou não ver qualquer inconveniente em apoiar resolução que proibisse a importação de resíduos perigosos. Paralelamente, em um de seus raros períodos proativos, o Ministério do Meio Ambiente estava preparando legislação nacional visando eliminar as últimas exceções para importação de resíduos perigosos, entre eles o chumbo.

Em Genebra, no entanto, a própria delegação brasileira é surpreendida por novas instruções chegadas de Brasília. O Brasil não apoiaria uma resolução que proibisse a exportação de resíduos perigosos para países em desenvolvimento, já que ele próprio necessitava de alguns desses resíduos, como o chumbo.

Isolado, porém, nessa posição dentro do Grupo Latino-Americano e do Caribe (Grulac), o Brasil, que além do mais fora escolhido com o porta-voz do grupo junto ao G-77, teve que ceder à posição consensual dos demais 
e endossar a proposta de proibição. Novamente apresentada ao plenário da $2^{\mathrm{a}}$ Reunião das Partes pelo G-77, após árduas negociações, ela foi aprovada. Decisivo para esse desenlace foi a formação da União Européia, forçando Inglaterra e Alemanha, grandes oponentes da proibição a aceitarem a posição majoritária dos outros membros da União, favoráveis à proibição. ${ }^{2}$

Nos meses que se seguiram, o bloco dos países exportadores, EUA, Canadá e Austrália, rearticulou-se, buscando invalidar os efeitos da Probição da Basiléia. Endossaram a proposta feita pela Inglaterra, anterior à formação da União Européia, de transformar em emenda ao texto da Convenção apenas a parte da resolução que mencionava a proibição de exportação de resíduos perigosos com vista ao despejo final. Com isso, deixava-se de fora justamente aquela parte mais significativa do tráfico de resíduos perigosos que ia parar nas fundições secundárias dos países em desenvolvimento, classificado como resíduo exportado para reciclagem ou recuperação.

Para contornar essa manobra, a Dinamarca apresentou proposta de transformar em emenda à Convenção o texto integral da resolução aprovada no ano anterior. Quando da $3^{\mathbf{a}}$ Reunião das Partes, em setembro de 1995, também em Genebra, uma distribuição de forças ligeiramente diferente se configurou: de um lado o bloco EUA, Canadá, Austrália, Japão e aliados e de outro o G-77, ainda que com algumas defecções, mas com o apoio de toda a União Européia.

O Brasil chegou a Genebra com uma delegação numerosa, tendo a sua frente um diplomata de grande experiência na área de direito ambiental, defendendo a tese de que não era necessário emendar a Convenção, pois resoluções adotadas livremente por países em convenções internacionais deveriam ter força de lei, ou seja, efeito vinculante. Esse argumento técnico, no entanto, servia apenas como desculpa para a recusa do Brasil em apoiar a proposta de emenda da Dinamarca. Durante as negociações e mesmo em entrevista à imprensa brasileira, a delegação brasileira deixava transparecer a real razão de sua recusa em apoiar a emenda dinamarquesa: sua postura contrária à proibição aprovada no ano anterior.

Novamente, no entanto, o Brasil tinha pouco espaço de manobra. Premido entre os dois blocos, acabou por ter que engolir a proposta dinamarquesa, quando esta foi aprovada por consenso, depois que as últimas resistências do bloco EUA, Canadá, Austrália e Japão foram vencidas.

Na verdade, a saída de Rubens Ricúpero do Ministério do Meio Ambiente tinha permitido que os setores econômicos ligados à metalurgia ocupassem vácuos de poder ali deixados. O grupo de funcionários do ministério que tentava desenvolver uma política ambiental para resíduos foi desbaratado e o ministério chegou mesmo a promulgar uma resolução ad hoc do Conama, às vésperas do Natal, que deixava a exclusivo critério do Ministro do Meio Ambiente autorizar a importação de resíduos perigosos quando fosse de interesse nacional.

Além disso, o Greenpeace descobriu troca de correspondência entre o Ministério do Meio Ambiente e o Departamento de Estado dos EUA, visando a elaboração de um tratado bilateral, que permitisse ao Brasil importar resíduos perigosos dos EUA.

Em 1996, o Ministério do Meio Ambiente de Gustavo Krause mobilizou-se ativamente para encontrar uma solução para alguns importadores de baterias usadas, em especial para a empresa Baterias Moura, localizada na sua área eleitoral, em Pernambuco. Uma resolução do Ministro autorizando a importação para várias indústrias, teve de ser cancelada, graças à pressão do Conselho Nacional de Meio Ambiente (Conama), impressionado com o dossiê trazido pelo Greenpeace e a Aspan (Associação Pernambucana de Proteção à Natureza), evidenciando com fotos e análises laboratoriais a contaminação do solo e das águas com chumbo provocada pela Baterias Moura (Lisboa e Rocha, 1997).

Consultado pelos Ministérios de Minas e Energia, Indústria e Comércio e Meio Ambiente sobre como driblar a Proibição da Basiléia que vigoraria em fins de 1997, de modo que o País pudesse continuar a importar resíduos perigosos, o Itamaraty prometeu negociar um perdão especial para o Brasil, embora felizmente a Convenção da Basiléia não contivesse esse dispositivo. O prazo de mais de 3 anos, após a aprovação da proibição, em março de 1994, fora dado justamente para que os países tivessem tempo para tomar as providências necessárias.

Na quarta reunião da Convenção da Basiléia, em Kuala Lumpur, Malásia, em fevereiro de 1998, a mesma estratégia hesitante foi adotada por nossa delegação. Desta vez a ameaça à Proibição da Basiléia vinha do pedido israelense para que se permitisse a inclusão de novos países na lista dos que não poderiam exportar para os países em desenvolvimento, o famoso Anexo VII. Caso isso fosse possível, países como o Brasil poderiam ingressar nesse anexo e, embora impedidos de enviar seus resíduos para outros países em desenvolvimento, poderiam receber dos países que normalmente exportam resíduos perigosos, como os EUA, Alemanha e outros. A delegação brasileira, numerosa, como sempre não expunha publicamente sua posi- 
ção, embora continuasse disputando um papel de liderança entre os países em desenvolvimento, tendo obtido, também, a representação do Grulac. Em conversas privadas, no entanto, externava a opinião de que a proibição de importar resíduos perigosos prejudicava a economia brasileira, "impedindo-a de reciclar metais pesados a preços competitivos, ao mesmo tempo em que se criava um mercado cativo para os países desenvolvidos". Era impressionante, portanto, a total ignorância sobre a problemática ambiental propriamente dita, ou seja, sobre o fato de que reciclar resíduos de metais pesados é uma operação sempre ambientalmente prejudicial, não havendo tecnologias capazes de evitar a contaminação do meio ambiente e dos trabalhadores com seus poluentes (Lisboa, 2000). A $4^{\mathrm{a}}$ Conferência da Basiléia foi concluída, no entanto, com a derrota da proposta de abrir o Anexo VII. Uma frente que reunia o G-77, liderada pelos países árabes, que temiam a contaminação da Ásia Menor com os resíduos perigosos que Israel pretendia importar e reciclar em seu território, foi capaz de enterrar essa última tentativa de reverter a Proibição da Basiléia.

O décimo aniversário da Convenção da Basiléia, durante a $5^{\mathrm{a}}$ Reunião das Partes, realizada na própria cidade em Basiléia, foi comemorado com grande pompa. Autoridades internacionais e ministros do meio ambiente reconheciam ser esta uma convenção ambiental de significado estratégico para o planeta, evitando que o mundo em desenvolvimento se tornasse a lixeira do Primeiro Mundo, ao mesmo tempo em que direcionava esse último para a chamada produção limpa, ao lhe proibir a solução fácil da exportação de lixo perigoso. Por isso mesmo, o presidente do Programa das Nações Unidas para o Meio Ambiente, Klaus Töpfer, encarecidamente pedia aos paísespartes da Convenção que ratificassem a emenda aprovada em 1995 (Töpfer, 1999). O Itamaraty, no entanto, discordava dessa interpretação, ainda que não abertamente. Encarava como uma discriminação injustificável ao livrecomércio, proibir um grupo de países "de receber resíduos perigosos" e defendia a tese de que países que tivessem tecnologias apropriadas deveriam ser autorizados a importar esses resíduos. Por isso mesmo, o Itamaraty propositalmente tem retardado até hoje os procedimentos referentes à ratificação da emenda aprovada em 1995.

\section{PROTOCOLO DE CARTAGENA}

O surgimento das plantas e animais transgênicos sinalizou uma nova área de perigo ambiental para o planeta: a biossegurança. Escapes de material transgênico podem trazer riscos significativos ao meio ambiente e a saúde humana, como a perda de biodiversidade - plantas, insetos, microorganismos - e o desenvolvimento de novas enfermidades. Como se tratam de seres vivos, que se reproduzem espontaneamente, eventuais incidentes dificilmente serão controlados, podendo inclusive ser irreversíveis. Isso motivou a Convenção sobre a Diversidade Biológica elaborar um protocolo de biossegurança, que deveria criar dispositivos que permitissem aos países-membros controlar o comércio de organismos geneticamente modificados, evitando que os movimentos transfronteiriços dessas substâncias pudessem trazer danos a seus territórios e suas populações. Sua lógica interna estruturava-se em torno do chamado Princípio de Precaução, princípio fundamental do direito ambiental, que estipula que caso haja indícios de que riscos de monta possam ocorrer ao meio ambiente, as autoridades não devem alegar à falta de evidência científica como desculpa para não tomar as providências adequadas (Tickner, 1999). Portanto, com base no Princípio da Precaução, o protocolo pretendia conferir aos países-partes o direito de recusar a importação de organismos geneticamente modificados, caso esses países considerassem que tais importações poderiam trazer danos a seu meio ambiente, saúde e economias.

Contrários a essa formulação, de um lado, tínhamos o chamado Grupo de Miami, formado pelos EUA, Canadá, Argentina, Austrália, Chile e Uruguai. Os três primeiros, produtores de transgênicos e defendendo seus interesses. Sendo a Austrália uma tradicional aliada dos EUA nas questões ambientais internacionais, o que havia de surpreendente no Grupo de Miami era a presença do Chile e do Uruguai, que não são produtores de transgênicos. O Grupo de Miami, na verdade, era uma inteligentíssima manobra diplomática dos EUA, capturando países que eram membros tradicionais do G-77, como a Argentina, o Chile e o Uruguai e inviabilizando, conseqüentemente, uma articulação do G-77 como oposição ao Grupo de Miami. Favoráveis ao Princípio de Precaução e ao "direito de dizer não" aos transgênicos, estavam todos os países da África, a maioria dos países asiáticos e também a maioria dos países latino-americanos. Para opor-se ao Grupo de Miami, formou-se o Grupo dos Like-Minded. A União Européia, que não apresentava uma posição tão firme com relação ao direito de dizer não, constituía o terceiro grupo importante na mesa das negociações.

Durante os 13 dias de negociações em Cartagena, na Colômbia, os representantes da delegação do Brasil não 
defenderam as mesmas posições nos diversos grupos de trabalho. Isso se explica, em parte, em razão da composição da própria delegação. Incluindo diversos representantes da Comissão Técnica de Biossegurança (CTN-Bio), subordinada ao Ministério de Ciência e Tecnologia e que vinha patrocinando a introdução dos transgênicos no Brasil desde a sua formação, a delegação contava com apenas um representante do Ministério do Meio Ambiente e três diplomatas. Além dessa falta de um consenso interno e de disciplina por parte dos membros da CTN-Bio, que externavam suas opiniões pessoais como se fossem as oficiais, agregaram-se as pressões vindas dos EUA e das multinacionais presentes no Brasil, exigindo que o Itamaraty abandonasse sua posição favorável à inclusão do Princípio de Precaução nos parágrafos operativos do texto da Convenção. Alertado pelo Greenpeace, o ministro do Meio Ambiente teve que interceder diretamente junto ao presidente da República, para que se mantivesse o que se estava considerando como um princípio ambiental, há muito acatado pela diplomacia brasileira.

O fracasso das negociações de Cartagena levou o então presidente da Conferência de Diversidade Biológica, o ministro do meio ambiente da Colômbia, Juan Mayr, a convocar uma reunião informal em Viena, visando acelerar as negociações entre o Grupo de Miami, o Grupo dos Like-Minded e a União Européia. Novamente trazendo uma composição heterogênea, com franco predomínio da turma da CTN-Bio, a atuação da delegação brasileira na reunião de Viena foi ainda mais errática do que a de Cartagena. Isolava-se do Grupo dos Like-Minded quanto à redação do artigo que definia as relações entre o futuro protocolo e outras Convenções, somando forças com o Grupo de Miami. A questão aí oculta era a possibilidade de que países fossem processados por ferirem cláusulas da Organização Mundial do Comércio, caso não quisessem autorizar a importação de transgênicos. Em defesa de sua posição, o Brasil alegava que "o direito de dizer não" poderia ser usado como "barreira não alfandegária". Alguns países do Grupo dos Like-Minded chegaram a externar a opinião de que o Brasil estaria intencionalmente atrapalhando a definição de uma posição conjunta por parte do Grupo e, assim, dificultando as negociações.

Nesse quadro de indefinições, o Protocolo de Biossegurança foi para sua última rodada de negociações em Montreal, em janeiro de 2000. Sob enorme pressão de organizações não-governamentais, cooperativas de camponeses e entidades de consumidores, cujas manifestações externas do centro de Convenções, com temperatura de $-30^{\circ}$, impressionam vivamente a mídia internacional, o Protocolo foi finalmente assinado. Dessa vez, o Grupo dos Like-Minded não esteve sozinho. Alguns ministros do Meio Ambiente da União Européia vieram pessoalmente participar das negociações e defenderam energicamente o Princípio da Precaução e a independência do futuro Protocolo diante de outras convenções, como a da Organização Mundial do Comércio.

Já tendo adquirido fama de confusa e não confiável, a delegação brasileira continuou atuando da mesma forma, sendo comum ver-se os representantes brasileiros da CTNBio saindo e entrando na sala do Grupo de Miami, a todo momento.

Finalmente, em maio de 2000, durante a $5^{\text {a }}$ Reunião da Convenção da Diversidade Biológica, em Nairobi, quando o Protocolo de Biossegurança foi aberto solenemente para assinaturas, uma surpresa. Enquanto países do Grupo de Miami como a Argentina e o Chile assinaram o Protocolo e Canadá e Austrália anunciaram que provavelmente viriam assiná-lo, depois de consultas internas, ${ }^{3}$ o Brasil comunicou que ainda não poderia assiná-lo, porque estava aguardando resposta de seus diferentes ministérios. Já se está em 2002 e parece que tais respostas não chegaram, embora a Esplanada dos Ministérios tenha sido especialmente desenhada para facilitar os contatos entre esses diversos órgãos do poder executivo.

A questão que se coloca, é: qual é, afinal, a posição brasileira com relação ao Protocolo de Biossegurança? É favorável ou é contrário, e por quê? Em defesa do Itamaraty deve-se reconhecer que o Executivo brasileiro, em sua totalidade, não tem uma posição clara quanto à liberação no meio ambiente de plantas e animais transgênicos. Enquanto o Ministério da Ciência e Tecnologia, durante os mandatos Israel Vargas e Bresser Pereira, advogou publicamente a favor dessa liberação, apoiado pelo Ministério da Agricultura de Francisco Turra, o Ministério do Meio Ambiente resistia discretamente por meio do Ibama, bem como o Ministério da Justiça defendia uma rotulagem plena para os alimentos transgênicos. Mais tarde, a mudança ministerial leva um Pratini de Morais a assumir papel protagônico na defesa dos transgênicos, enquanto o novo ministro da Ciência e Tecnologia, Sardenberg, adota uma postura mais discreta. A Justiça Federal, em sucessivos julgamentos em primeira e segunda instância, dá ganho de causa para o Greenpeace e o Idec, impedindo o plantio de transgênicos sem que haja estudo de impacto ambiental, mas a União entra como litisconsorte, ao lado da Monsanto e força o Ibama, com medida provisória, a se retirar da 
causa, com o Greenpeace e ao Idec. Seria compreensível, portanto, que o Itamaraty não tivesse uma postura muito clara para apresentar. O que é estranho, sim, é que havendo participado das negociações e do acordo consensual em torno ao texto final do Protocolo de Cartagena, recusou-se a assiná-lo, com todos os custos políticos que essa atitude implicaria, quando até os seus maiores oponentes já o haviam feito, como a Argentina e o Chile.

\section{CONVENÇÃO DE ESTOCOLMO}

A Convenção de Estocolmo, sobre os Poluentes Orgânicos Persistentes, começou a ser negociada em 1995, quando o Programa de Meio Ambiente da ONU formou um grupo de trabalho para analisar as políticas a serem adotadas em relação aos poluentes orgânicos persistentes. Perigosos por serem persistentes no meio ambiente e bioacumulativos, ou seja, transferindo-se ao longo da cadeia alimentar, os poluentes orgânicos persistentes, comumente chamados de POPs são, entre outras coisas, cancerígenos, disruptores do sistema endócrino e supressores do sistema imunológico. Na maioria dos casos muito voláteis, são carregados pelas correntes atmosféricas desde as regiões mais quentes do planeta, condensandose nas baixas temperaturas das áreas próximas aos pólos, aí se depositando. As correntes marítimas também encarregam-se de distribuir esses poluentes por todo o planeta, transformando-os em poluentes globais. Cinco reuniões internacionais foram necessárias para preparar o texto da Convenção, que finalmente foi aprovado em maio desse ano, em Estocolmo. O principal dispositivo da Convenção é a decisão de se eliminar a produção e consumo de 12 dos piores POPs, grande parte deles, agrotóxicos já proibidos na maioria dos países. Ponto de especial disputa, no entanto, era o artigo que definia que os países deveriam adotar medidas para eliminar também aqueles POPs de produção não intencional, como as dioxinas e furanos, que são produzidos sem que se possa evitar sua formação, nas indústrias que utilizam o cloro. Ainda que o artigo deliberadamente adotasse uma formulação ambígua, propondo que a eliminação desses POPs ocorresse apenas quando viável, a indústria química opunha-se resolutamente a essa idéia, tendo seu ponto de vista defendido com toda a energia pelos EUA, Canadá, Austrália e Japão. Na delegação brasileira, a indústria química esteve presente em todas as negociações, por intermédio um representante da Abiquim, muito ativo. Foi ele o autor da proposta, que exigiu enormes esforços para ser retirada posteriormente, de que o artigo referente aos POPs não intencionais se redigisse de modo que só adotasse medidas de eliminação caso elas fossem técnica e economicamente viáveis. Manifestamente, as delegações brasileiras tinham problemas com o Princípio da Precaução, presente tanto na introdução da Convenção, como em seus parágrafos operativos. Embora o Brasil já tivesse aceitado a inclusão do Princípio da Precaução em diversos outros acordos internacionais, relutou até a última hora em dar seu apoio a inclusão desse princípio nessa convenção, alegando que a conferência estava alterando sua formulação clássica. Além de retornar ao clássico argumento brasileiro, de que o Princípio da Precaução pode ser usado com barreira não-tarifária contra os países em desenvolvimento. Entretanto, a surpresa maior veio quando a Convenção de Estocolmo foi assinada, em maio de 2001. O Brasil assinava o texto, mas pedia uma exceção de uso, de seis anos para um dos agrotóxicos a serem eliminados, o heptacloro. Utilizado no passado para tratamento de madeira, para evitar cupim, o heptacloro foi abandonado paulatinamente por ser altamente tóxico, e por existirem alternativas menos perigosas no mercado. A última fábrica que produzia o heptacloro, a empresa norte-americana Vesicol, fechou suas portas há dois anos, nos EUA. No entanto, a empresa brasileira Action, que comprou os estoques da Vesicol, conseguiu que o ministério de Indústria e Comércio intercedesse a seu favor, vencendo as resistências, aliás sempre débeis, do Ministério do Meio Ambiente. Em virtude dessa fábrica, assim como no caso da Basiléia, por causa das Baterias Moura, o Brasil solicitou uma exceção especial, contrariando o esforço coletivo de eliminar no mais curto espaço de tempo possível e em todos os casos para os quais haja alternativas, esses perigosos poluentes.

\section{FALSO DILEMA}

A causa principal da mediocridade de que padece a política externa brasileira de meio ambiente parece residir na própria concepção errônea do que venha a ser uma política ambiental para o Itamaraty. Nossos diplomatas ainda concebem a questão ambiental de forma isolada, separada das demais atividades humanas relacionadas à economia. De fato, é comum ouvir dos nossos representantes diplomáticos afirmações do tipo, "se por um lado o Brasil se preocupa em defender o meio ambiente, por outro lado, por ser uma potência industrial, não pode permitir que princípios ecologistas venham a prejudicar a economia, o emprego e o progresso material e científico do país". 
Ora, separar economia e meio ambiente como se fossem dois lados estanques e complementares de uma realidade qualquer, indica que o já velho conceito do desenvolvimento sustentável dos anos 70 ainda não chegou a ser compreendido em seu conteúdo substantivo. Uma economia sustentável do ponto de vista ambiental é uma economia que não destrói suas próprias condições de existência. Por isso, não pode haver a contradição entre uma boa política ambiental e uma boa política econômica. O que é mau para o meio ambiente é mau também para a economia, ainda que a tradução dos danos ambientais em prejuízos econômicos possa não ser perceptível a curto prazo. Mais tarde ou mais cedo os custos ambientais serão infalivelmente cobrados em saúde pública, qualidade de vida, esgotamento de recursos naturais e desvalorização de bens materiais e imateriais.

A separação entre economia e ecologia, portanto, é uma miopia. Ao contrário, a economia deveria subordinar-se à ecologia, que, como ciência dos ecossistemas, estuda a base física na qual qualquer tipo de economia pode estruturar-se (Alier e Schlupmann, 1991). Desenvolvimento sustentável, portanto, é aquele tipo de desenvolvimento que garante a permanência dessa base física.

A chegada da filosofia neoliberal ao departamento de meio ambiente do Itamaraty, o Dema, em meados dos anos 90, só pode piorar as coisas. Esse credo neoliberal condenará medidas políticas que proíbam atividades consideradas prejudiciais ao meio ambiente, como inócuas e contraproducentes. Defenderá a tese de que os incentivos econômicos são o único gênero de política capaz de provocar mudanças de comportamento e que a excessiva ingerência do Estado na atividade econômica por meio de políticas ambientais pode levar a uma atrofia dessas atividades. Além disso, grande parte das restrições estabelecidas pelos acordos ambientais internacionais às atividades consideradas como prejudiciais ao meio ambiente passaram a ser interpretadas como "barreiras não-tarifárias", formas de cercear as exportações dos países em desenvolvimento nos mercados do Primeiro Mundo.

Dividido quanto a que partido tomar entre o meio ambiente e a economia, a saída do Itamaraty freqüentemente tem sido a busca de um meio termo, de uma média entre o que seriam os interesses ambientais e os interesses econômicos. Favorece as soluções mais moderadas, propõe a dilatação dos prazos para adoção de medidas, avança com prudência infinita, configurando um estilo de política que, no nosso próprio país, chamaríamos de "ficar em cima do muro".
A concepção de política ambiental como uma média a ser tirada entre os diversos "aspectos" de uma problemática, ilustra-se magistralmente pela forma como o Itamaraty realiza suas reuniões preparatórias para negociações de convenções internacionais de meio ambiente. Os diversos ministérios que possam considerar-se atingidos por determinada problemática ambiental são convidados para debater a política a ser definida. Além dos Ministérios do Meio Ambiente e do Ministério da Indústria e Comércio, poderão estar presentes o Ministério da Saúde, se houver algum vínculo direto com a saúde, bem como Minas e Energia, Fazenda, Ciência e Tecnologia. Representantes do setor industrial e organizações não-governamentais ambientalistas também poderão ser convidados para expor suas preocupações. Como não podia deixar de ser, nessas reuniões o Ministério do Meio Ambiente é sempre minoria, ainda que conte com o apoio das organizações não-governamentais, forçando matematicamente as posições a serem defendidas pelo Brasil a favorecer, antes de tudo, os interesses econômicos do curto prazo, defendidos ciosamente pelos ministérios da Indústria, Fazenda, Minas e Energia.

Esse procedimento para tomada de decisão não permite a elaboração de uma política ambiental. Não há um conjunto de princípios que norteie as posições adotadas, um conjunto de objetivos e estratégias e alianças visando alcançar esses objetivos. Enquanto em uma convenção apoiamos certos princípios, em outra podemos rejeitá-los. Tampouco há uma continuidade nas posições assumidas no interior de uma mesma negociação. Mudam nossas posições ao sabor dos representantes diplomáticos enviados e não há qualquer preocupação em garantir que não se perca a memória e a experiência acumulada pelos diplomatas que são transferidos de setor.

\section{DIFÍCIL LIDERANÇA}

O curioso dessa situação é que ela contraria o objetivo tão caro à diplomacia brasileira de situar o País como potência mundial, pois a tibieza e a omissão não costumam chamar a atenção. Discursos bem construídos, delegações numerosas e manobras diplomáticas para garantir o posto de porta-voz do Grulac e do G-77, grupo que reúne os países em desenvolvimento, contrasta com a pobreza das propostas por nós apresentadas e com a nossa falta de clareza sobre o que queremos. Os EUA e o Canadá, por exemplo, destacam-se por serem sempre contra quaisquer avanços em matéria de legislação ambiental internacional. Os 
EUA não assinaram a Convenção sobre a Diversidade Biológica, a Convenção da Basiléia, e batem o pé em não assinar o Protocolo de Kyoto. Os países nórdicos, ao contrário, em geral estão na vanguarda das questões ambientais. Em aliança com os países em desenvolvimento, o G-77, Suécia, Dinamarca e Noruega sempre estão à frente das grandes negociações em andamento. A Colômbia, na América Latina, tradicionalmente tem posturas ousadas e coerentes em prol do meio ambiente, enquanto a Argentina secunda, quase sempre, os EUA. Os países africanos, unidos em um bloco sólido pela Organização da União Africana (OUA), transformaram sua fragilidade em fortaleza. Do Brasil, no entanto, quase nada que mereça destaque pode ser apontado, na política ambiental.

\section{RESPONSABILIDADES COMUNS, MAS DIFERENCIADAS}

É preciso reconhecer, no entanto, a parte da culpa que cabe ao Ministério do Meio Ambiente nessa questão. Com exceção do período de Lutzemberg, quando o Ministério ainda era Secretaria do Meio Ambiente e do curto período do Rubens Ricúpero, todos os demais ministros do Meio Ambiente foram incapazes de pressionar o Itamaraty para que adotasse qualquer política externa ambiental coerente. Na maioria dos casos, porque eles próprios não possuíam qualquer entendimento a respeito da questão ambiental e, portanto, tampouco tinham qualquer coisa a sugerir como política externa. Alguns deles ganharam o ministério do Meio Ambiente na tradicional divisão do bolo ministerial entre partidos e regiões, deixando que o segundo escalão continuasse fazendo o que bem lhe aprouvesse, desde que não lhes criasse problemas com seus protegidos. Quando isso acontecia, no entanto, os funcionários zelosos eram desautorizados e transferidos de cargo, convergindo tudo isso, ao fim, para um total imobilismo da máquina governamental.

José Sarney Filho é, de fato, o primeiro ministro do Meio Ambiente que entende de Meio Ambiente, se excluirmos Lutzemberg, um dos fundadores do movimento ambientalista brasileiro e Rubens Ricúpero, diplomata de carreira, que embora não fosse da área, dominava bastante bem a problemática da floresta amazônica, tendo sido um dos articuladores principais da Eco-92. Infelizmente, no entanto, José Sarney Filho não demonstra qualquer interesse pela política externa ambiental. Aliás, mesmo nacionalmente, seu interesse restringe-se à questão da proteção à Amazônia e Mata Atlântica, abandonando inteira- mente ao Itamaraty as temáticas referentes à poluição química e à segurança biológica. É freqüente a situação em que o Ministério do Meio Ambiente não envia representantes seus para integrar as delegações diplomáticas brasileiras nas negociações internacionais de meio ambiente, alegando falta de recursos.

Já o mesmo não ocorre com os demais ministérios como o da Agricultura, Ciência e Tecnologia, Indústria e Comércio e Minas e Energia, que estão sempre presentes nas delegações diplomáticas enviadas às convenções de meio ambiente. Como o Ministério do Meio Ambiente manifesta pouco interesse em defender os interesses difusos em jogo nas questões internacionais, de um lado, e de outro os ministérios da área econômica são resolutos na defesa daqueles interesses econômicos, que além disso costumam ter nome, endereço e padrinhos políticos, o Itamaraty tende naturalmente para a defesa dos últimos.

\section{CLIMA, UM CASO À PARTE}

O caso da Convenção das Mudanças Climáticas permite analisar a diferença que um Ministério pode fazer na elaboração de uma política diplomática coerente e inteligente para o meio ambiente. Por circunstâncias que aqui não cabe desenvolver, alguns altos funcionários do $\mathrm{Mi}$ nistério de Ciência e Tecnologia e de outros institutos de pesquisa vieram acompanhando as negociações para a elaboração da Convenção das Mudanças Climáticas desde o seu início, antes da Eco-92. Participando da definição dos princípios básicos em que se deveria basear essa convenção, o Princípio da Precaução e o das Responsabilidades Comuns, mas diferenciadas e das principais medidas para controle das mudanças climáticas, bem como desenvolvendo cálculos e propostas específicas, como as do mecanismo limpo, o Brasil se impôs, assim, como um dos mais importantes negociadores no cenário diplomático dessa convenção. É isso que confere ao nosso país, hoje, autoridade moral para criticar o Presidente Bush, por sua recusa em assinar o Protocolo de Kyoto.

Vale comentar, no entanto, que aquilo que se exige hoje, do Brasil, para cumprir com seus compromissos diante dos demais países-partes da Convenção de Mudanças Climáticas não afeta quaisquer interesses econômicos a curto prazo em nosso país. Como o Brasil não se encontra entre os países do Anexo I, os que possuem a maior responsabilidade histórica nas mudanças climáticas que hoje experimentamos, e que, portanto, devem em primeiro lugar reduzir suas emissões de gases estufa, não se está exigin- 
do da economia brasileira nenhuma mudança drástica em sua forma de atuar. Nessas circunstâncias, é fácil cobrar dos EUA e outros países suas responsabilidades, o que soa ainda menos sincero quando consideramos que as emissões brasileiras de gases estufa estão aumentando em uma velocidade assustadora e não há sinais de que se esteja considerando quaisquer medidas para reduzir esse crescimento. O complexo industrial automobilístico continua merecendo incentivos do governo federal bem como dos governos estaduais, em guerra fiscal na disputa de fábricas automobilísticas. Grande parte das verbas de transporte e construção civil são destinadas à infra-estrutura necessária para expandir o transporte de carga e de passageiros automotivo. O Proálcool foi abandonado assim que o preço do petróleo baixou, embora se tratasse de combustível renovável, portanto, não prejudicial ao clima. A eclosão da recente crise energética veio promover dezenas de termoelétricas a gás e mesmo algumas a carvão - o pior dos combustíveis fósseis para as emissões de dióxido de carbono na atmosfera -, ameaçando modificar o perfil de nossa matriz energética, que até então baseada em hidroeletricidade, não contribuía significativamente para as mudanças climáticas. Por outro lado, as políticas para combater o desmatamento e as queimadas, a principal forma de contribuição do Brasil às mudanças climáticas, continuam débeis e ineficientes.

Tomando como exemplo a posição brasileira na questão das mudanças climáticas, poderíamos dizer que a receita para uma boa política ambiental externa parece ser, em primeiro lugar, a ausência de quaisquer pressões econômicas contrárias à essa política. Em seguida, é importante que haja uma área técnica, possuidora de massa crítica capaz de analisar a problemática em questão e propor soluções - como é o caso do Ministério de Ciência e Tecnologia e, finalmente, uma boa diplomacia. Uma receita difícil de se reproduzir em outros temas ambientais, como se viu nos três exemplos que iniciam esse artigo. Lamentavelmente, pois, a gravidade da crise ambiental pela qual atravessa o planeta exige respostas rápidas e responsáveis por parte de toda a comunidade internacional.

\section{NOTAS}

1. A Convenção de Londres surgiu em 1973, logo após a Conferência de Estocolmo para o Meio Ambiente, e tinha como objetivo regulamentar o despejo de resíduos perigosos no mar. Em 1985 adotou uma moratória indefinida para despejo de resíduos radioativos de baixo teor e em 1988 propôs a suspender a incineração de resíduos líquidos em navios, que entrou em vigor em 1990. Nesse mesmo ano, decidiu-se suspender o despejo de resíduos industriais nos oceanos, o que foi efetivado em 1995.

2. Sobre as condições políticas que levaram a que toda a União Européia apoiasse a Proibição da Basiléia ver tese de doutoramento da autora (Lisboa, 2000).

3. Os EUA sequer assinaram a Convenção da Diversidade Biológica e, por isso, não poderiam assinar o Protocolo de Cartagena, que é um instrumento negociado dentro dos marcos dessa Convenção.

\section{REFERÊNCIAS BIBLIOGRÁFICAS}

ALIER, J. e SCHLUPMANN, K. La ecologia y la economia. Cidade do México, Fondo de Cultura Económica, 1991.

LISBOA, M. A proibição da Basiléia: ética e cidadania planetárias na era tecnológica. Tese de Doutoramento. São Paulo, Programa de Pós-Graduação em Ciências Sociais da PUC-SP, 2000.

LISBOA, M. e ROCHA, S. Chumbo grosso: o caso das Baterias Moura. São Paulo, Greenpeace e Aspan, 1997.

TICKNER, J. “A Map Toward Precautionary Decision Making”. In: RAFFENSPERGER, C. e TICKNER, J. (orgs.). Protecting Public Health and the Environment: Implementing the Precautionary Principle. Washington DC/Covelo, 1999.

TÖPFER, K. "Editorial”. Notre planète. Nairobi, PNUD, v.2, n.4, 1999.

Marijane Vieira Lisboa: Socióloga, Diretora Executiva do Greenpeace, Professora de Sociologia dos cursos de Relações Internacionais e Ciências Sociais da Faculdade de Ciências Sociais da PUC-SP. 